\title{
Correction to: Potential toxicity of trace elements and nanomaterials to Chinese cabbage in arsenic- and lead- contaminated soil amended with biochars
}

\author{
Yasser Mahmoud Awad $\cdot$ Meththika Vithanage $\cdot$ Nabeel Khan Niazi • \\ Muhammad Rizwan · Jörg Rinklebe · Jae E. Yang • Yong Sik Ok • \\ Sang Soo Lee
}

Published online: 27 December 2017

(C) Springer Science+Business Media B.V., part of Springer Nature 2017

\section{Correction to: Environ Geochem Health https://doi.org/10.1007/s10653-017-9989-3}

Unfortunately, in the original publication of the article, Prof. Yong Sik Ok's affiliation was incorrectly published. The author's affiliation is as follows.

1. Kangwon National University, Chuncheon 24341, Republic of Korea

The original article can be found online at https:// doi.org/10.1007/s10653-017-9989-3.

Y. M. Awad · M. Vithanage · Y. S. Ok $(\bowtie)$.

S. S. Lee $(\square)$

Korea Biochar Research Center and School of Natural Resource and Environmental Sciences, Kangwon National University, Chuncheon 24341, South Korea

e-mail: soilok@kangwon.ac.kr

S. S. Lee

e-mail: sslee97@kangwon.ac.kr

\section{Y. M. Awad}

Department of Agricultural Botany, Faculty of Agriculture, Suez Canal University, Ismailia 41522,

Egypt

M. Vithanage

Chemical and Environmental Systems Modeling Research Group, National Institute of Fundamental Studies,

Kandy 20000, Sri Lanka
2. O-Jeong Eco-Resilience Institute (OJERI), Division of Environmental Science and Ecological Engineering, Korea University, Seoul, Republic of Korea
N. K. Niazi

Institute of Soil and Environmental Sciences, University of Agriculture Faisalabad, Faisalabad 38040, Pakistan

N. K. Niazi

MARUM and Department of Geosciences, University of Bremen, 28359 Bremen, Germany

M. Rizwan

Department of Environmental Sciences and Engineering, Government College University, Allama Iqbal Road,

Faisalabad 38000, Pakistan

J. Rinklebe

Laboratory of Soil- and Groundwater-Management, Institute of Foundation Engineering, Water- and Waste Management, School of Architecture and Civil

Engineering, University of Wuppertal, Pauluskirchstraße 7, 42285 Wuppertal, Germany 
J. Rinklebe

Department of Environment and Energy, Sejong

University, Seoul 05006, South Korea

J. E. Yang

School of Natural Resource and Environmental Sciences, Kangwon National University, Chuncheon 24341, South Korea

Y. S. Ok

O-Jeong Eco-Resilience Institute (OJERI), Division of Environmental Science and Ecological Engineering,

Korea University, Seoul, Republic of Korea

e-mail: yongsikok@korea.ac.kr

\section{Springer}

